importance of having a manometer or release valve incorporated in the circuit has been stressed. Seed, Shakespeare, and Mul doon $^{1}$ stated that the inflow pressure should not rise above $20 \mathrm{~mm}$. $\mathrm{Hg}$, a higher pressure usually indicating a blocked cannula One of their patients suffered from tachycardia and a fall in blood pressure when the insufflation pressure rose above $40 \mathrm{~mm}$. $\mathrm{Hg}$ for a short time, but recovery occurred immediately on decompression. These authors attributed the hypotension to compression of the vena cava, and suggested that it was more likely to occur earlier with a tense abdominal wall than with flaccid musculature. Splinting of the diaphragm will also embarrass respiration and regurgitation of stomach contents may occur.

Once the dangers of overdistension are realized they can be easily avoided, but should this occur immediate release of pressure and raising the legs should quickly re store normal cardiac and respiratory function.-I am, etc.,

Humphrey ARTHURE.

London, W.1.

REFERENCE

1 Seed, R. F. Shakespeare, T. F., and Muldoon,
M. J., Anaesthesia, 1970, 25, 223.

\section{Vasovagal Faint in the Supine Position}

SIR,-The report by Drs. P. J. Verrill and W. H. Aellig (7 November, p. 348) of severe faint in a dental patient given diazepam lying down is interesting and important. One can only speculate on whether he would have survived had he been sitting up and had the injected drug been a general anaesthetic, when loss of consciousness would have been expected and therefore the onset of the faint perhaps overlooked.

May I correct a small misrepresentation in their final sentence? They quote Weissler and Warren ${ }^{1}$ as having stated that when fainting reactions occur in recumbent subjects they are particularly severe, often protracted, and associated with pronounced degrees of bradvcardia. In fact what Weissler and Warren were referring to was not the faint itself, but the prodromal symptoms of fainting. It is not surprising that these are often severe and protracted in recumbent subjects, since it is extremely rare in that position for consciousness to be lost.-I am, etc.

Salisbury, wilts.

J. G. Bourne.

REFERENCE

Weissler,
Heart fournal, W. 1959, 57, 786.

\section{Phenacetin Nephropathy}

SIR,-Dr. K. G. Koutsaimanis and Professor H. E. de Wardener (17 October, p. 131) give a timely reminder of the hazards of analgesic abuse, but their use of the term "phenacetin nephropathy" and their statements to the effect that it is only phenacetin which causes renal papillary necrosis cannot pass unchallenged. Although abuse of mixed analgesics is associated with papillary necrosis, it is most unlikely that phenacetin itself plays a major aetiological role. The salicylates and pyrazolones taken with it are much more likely to be the culprits. Let us re-examine the facts.

(1) Renal papillary necrosis has never been described in man in association with excessive consumption of phenacetin alone.

(2) Despite numerous determined efforts, it has proved virtually impossible to produce papillary lesions in experimental animals with phenacetin alone. Although Fordham et al. ${ }^{1}$ succeeded in producing papillary lesions in three out of 39 rats, they had to work up to $3,000 \mathrm{mg} . / \mathrm{kg}$. of phenacetin daily. This dose actually exceeds the acute oral L.D. . Compared with other drugs, phenacetin is remarkably non-toxic to the kidney.

(3) Phenacetin is invariably taken in combination with aspirin or pyrazolone derivatives such as antipyrine and amidopyrine. Unlike phenacetin, these anti-inflammatory drugs have consistently been shown to produce severe renal lesions including papillary necrosis in animals. ${ }^{2-5}$

(4) Renal papillary necrosis in man has been associated with heavy consumption of salicylates or pyrazolones. ${ }^{6-9}$ There is also a very high incidence of non-obstructive pyelonephritis and papillary necrosis in patients with rheumatoid arthritis, a condition in which salicylates are usually given in high dosage.

I do not believe that phenacetin is entirely harmless, but I am very concerned that the current obsession with phenacetin will delay recognition of the greater nephrotoxicity of the drugs taken with it. Aspirin in particular seems to be a dangerous wolf in very familiar sheep's clothing. Its defenders point to the very high overall national consumption of aspirin as compared with phenacetin as an index of its safety. But analgesic abusers very rarely take plain aspirin. They prefer analgesic combinations (which until recently invariably contained phenacetin), believing them to be "better" or "stronger."

Dr. Koutsaimanis and Professor de Wardener are trying to have their cake and eat it in their interpretation of the experimental studies of phenacetin. They dismiss the negative findings as being "difficult to assess," and consider that the production of papillary necrosis in rats by combinations of phenacetin and aspirin is "not relevant to what happens in man." Their exclusive condemnation of phenacetin seems surprising. I take issue with Dr. Koutsaimanis and Professor de Wardener over another point. They quote me (and many other authors) incorrectly as having reported cases of "phenacetin nephritis." I have never seen a patient with this condition and neither, I suspect, have they. They also state that "phenacetin nephritis" was first described by Spühler and Zollinger. ${ }^{10}$ In this article there is no mention of phenacetin (or acetophenetidin).-I am, etc.,

\section{F. Prescott}

\section{University Department of Therapeutics,} Roval Infirmary
Edinburgh.

REFERENCES

1 Fordham, C. C., Huffines, W. D., and Welt, L. G., Annals of Internal Medicine, 1965, 62 2 Fellers, F. X. Pradilla, A., and Craig, J. M., in
Progress in Pyelonephritis, ed. E. H. Kass, p. 337 Philadelphia, Davis, 1965
3 Clausen, E., Renal Damage Following Long-term Administration of Phenacetin and Acetylsalicylic Acid. Copenhagen, Munksgaard, 1967. British Nanra, R. S., and Kincaid-Smith,
Medical fournal, 1.970, 3, 559.

Brown, D. M., and Hardy. T. L., British fournal of Pharmacology and Chemotherapy, 1968, 32,

Prescott, L. F., Scottish Medical fournal, 1969 $14,82$.
Harvald,

Harvald, B., American fournal of Medicine, 1963 Ólafsson, Ó., Gudmundsson, K. R., and Brekkan, A., Acta Medica Scandinavica, 1966, 179, 121 .
Lawson. A. A. H., and Maclean, N., Annals of the Rheumatic Diseases, 1966, 25, 441. Spühler, O., and Zollinger, H. U., Zeitschrift für
klinische Medizin, 1953, 151, 1.

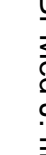

SIR,-Dr. K. G. Koutsaimanis and Professor H. E. de Wardener (17 October, p. 131) draw attention to apparent geographical differences in the incidence of renal papillary necrosis. Their estimate of the incidence of analgesic nephropathy in England and Wales is, however, much higher than that of Davies et al.,1 who recently reviewed records of 18,866 adult necropsies in Liverpool covering a period of $5 \frac{1}{2}$ years. They found 31 cases of renal medullary necrosis, an incidence of 1.64 per 1,000 necropsies. The commonest aetiological factor was urinary tract obstruction or diabetes. Five patients had a history of analgesic abuse.

Phenacetin is a component of the analgesic compounds most commonly abused, but the question of whether it is phenacetin alone which produces nephropathy remains an open one. Work done recently in Australia and South Africa has emphasized the need for a closer examination of the effects of mixtures, particularly of aspirin, phenacetin, and caffeine. Abrahams and Levinson ${ }^{2}$ in South Africa produced lesions of the renal papillae in rats fed with such mixtures. Kincaid-Smith and co-workers in Melbourne have reported a series of studies in which mixtures of analgesics, given at doses estimated to be equivalent to those consumed by some persons abusing analgesics, have produced renal damage. Drs. R. S. Nanra and P. Kincaid-Smith (5 September, p. 559) reported that nearly half their rats gavage-fed with aspirin and aspirin-containing mixtures developed papillary necrosis in 20 weeks. Aspirin alone produced necrosis in $36.8 \%$ of animals, whereas phenacetin in the same dose failed to cause any damage over 6 to 9 months. Brown and Hardy $^{3}$ studied the effects of large doses of phenacetin, phenazone, and amidopyrine on kidney function in rats. Phenazone caused a persistent celluria with evidence of slight kidney damage; amidopyrine caused papillary necrosis but little, if any, celluria. Phenacetin caused neither. Very little investigation appears to have been done into the possible part played by caffeine in the pathogenesis of analgesic nephropathy.

In including paracetamol in their recommendation that phenacetin be placed under stricter controls, the authors have not taken into account recent investigations into the metabolism of phenacetin. Paracetamol is indeed the principal metabolite in man but a number of others have now been identified. ${ }^{4}$ There is some evidence that genetic factors mav influence the route of metabolism. ${ }^{6}$ Raaflaub and Dubach ${ }^{7}$ have recently demonstrated a dose-dependent change in the pattern of metabolism of phenacetin in 
animals and man. When a dose of phenacetin was increased from $500 \mathrm{mg}$. to $2.5 \mathrm{~g}$. in human volunteers the formation and excretion of $p$-phenetidin and 2-hydroxyphenetidin sulphate were both enhanced. Neither of these is a metabolite of paracetamol. They concluded that, as a working hypothesis for further investigation to elucidate the pathogenesis of analgesic nephropathy, phenetidin deserved specia consideration. Prescott ${ }^{5}$ has commented that the metabolism, and possibly the toxicity of phenacetin, may be modified by the previous or concurrent administration of other drugs. There are therefore "logical reasons" for suggesting that the effect of paracetamol on the kidneys may well be different from that of phenacetin, particularly when phenacetin is consumed in large amounts.-We are, etc.

Joyce A. Abel. Robert A. MiLey.

Sterling-Winthrop Group Ltd.,
Surbiton, Surrey,

REFERENCES 1 Davies, D. J., Kennedy, A., and Roberts, C. Abrahams, C., and Levinson, C., South African Medical fournal, 1970, 44. 63.
Brown, D. M., and Hardy, T. L., British fournal of Pharmacology and Chemotherapy, 1968, 32 Klutch, A., Harfenist, M.. and Conney, A. H., Fournal of Medicinal Chemistry, 1966. 9, 63
Prescott, L. F., Sansur, M., Levin, W., and Conney, A. H. Clinical Pharmacology and
Therapeutics, 1968, 9. 605.

7 Shahidi N. T., Hospital Practice, 1968. 3. 73. Wochenschrift, 1969, 47, 1286.

\section{Treatment of Shock}

SIR,-In their recommendations for emergency treatment of myocardial infarction (3 October, p. 54) the physicians from the Chichester Postgraduate Medical Centre recommend intravenous injection of morphine $10 \mathrm{mg}$. or diomorphine $5 \mathrm{mg}$. Extensive experience with intravenous Cyclimorph convinces me that the emetic effects of morphine can be practically eliminated by the use of a harmless antiemetic such as cyclizine. I cannot see any reason for the continued practice of injecting plain morphine.

They also recommend that if there is hypotension the patient should be kept flat and the bed tilted head downwards. Although the Trendelenberg position is traditional for hypotensive shock ${ }^{1}$ the practical, theoretical, and experimental evidence indicates that a horizontal body with elevated limbs is the best position. The head down position will certainly produce immediate improvement compared with the upright posture because it results in the rapid transfer of blood from the limbs to the heart and vital organs.

But the head down position has two disadvantages compared with the horizontal position. Firstly, it causes the viscera to fall against the diaphragm, thus diminishing the volume of the chest, increasing the work of breathing and diminishing the negative pressure in the chest. ${ }^{2}{ }^{3}$ Secondly, it cannot increase the cerebral blood flow compared with the horizontal position because the arterial and venous pressures will be equally raised so that the theoretical net effect is nil. ${ }^{4}$ However, if the head down position is maintained for more than a short time it will result in oedema of the brain, which will diminish cerebral blood flow. ${ }^{5}$

These theoretical disadvantages are confirmed by experiments which demonstrate a higher mortality in the head down position, both in toxic hypotensive shock ${ }^{2}$ and in oligaemic hypotensive shock. $^{6}$

We have learnt that, in the resting patient, blood flow in the leg is maximal when the limb is horizontal ${ }^{7}$; the absence of valves in the veins of the skull and neck suggest that this is even more valid in the case of the cerebral circulation. Since the aim of treatment in hypotensive shock is to diminish the circulation in the limbs and increase the circulation in the brain and vital organs without embarrassing respiration the rational treatment is to keep the body horizontal and elevate the limbs. ${ }^{89}$

It took us a long time to realize that heating up shocked patients was irrational and harmful. How long will it take us to abandon the tradition of tipping the shocked patient head downwards? Perhaps our greatest difficulty in abandoning the old treatment is the fact that most hospital beds and resuscitation trolleys are not equipped to facilitate elevation of the limbs while maintaining the body horizontal.-I am etc.,

\section{Bridgend General Hospital,
Bridgend, Glam.}

A. W. FOWLER.

REFERENCES

London, P. S., A Practical Guide to the Care of the Injured, p. 19. Edinburgh, Livingstone, 1967 Surgery, Gynecology and Öbstetrics, 1963, 116, 669.

Weil, M. H., Circulation, 1957, 16, 1097

Resusth, W. G. In Cardiac Arrest an Resuscitation. Ed. H. E. Stephenson. 2nd edn. p. 1scilat. Lous,

J. Fournal of

Physiolocy, 1955, 130, 467

P. H. In Cardiac Arrest and Resuscitation. Ed. H. E. Stephenson. 2nd edn. St. Louis,

Beaconsfield, P., and Ginsburg, J., Circulation Research, 1955, 3. 478 .

Suraical R. M., Clinical Management of Shock,

Stephenson, H. E. Ed. Cardiac Arrest and
Resuscitation. 2nd edn. St. Louis, Mosby. 1964.

\section{Allergy to Iprindole (Prondole) with Hepatotoxicity}

SIR,-In 1968 I had under my care probably the first case of iprindole hepatotoxicity. He was a young man who had been attending my outpatient clinic at the London Jewish Hospital for chronic anxiety and depression. This was kept under moderate control with amitryptyline and diazepam but because of a relapse in his condition I changed his medication to iprindole $15 \mathrm{mg}$. t.i.d. with diazepam $5 \mathrm{mg}$. t.i.d. on 24 October 1968. One month later when he came to see me again at my clinic he was jaundiced and investigations after admission revealed that this was a case of hepatotoxicity. His jaundice and liver dysfunction cleared up satisfactorily after three weeks. I reported this case to the manufacturers of iprindole, John Wyeth \& Brother Ltd., and after studying the case records their scientific staff agreed with the diagnosis of drug toxicity.

However, despite this case, I have continued to use iprindole extensively, particularly with outpatients. I would disagree with Drs. D. F. Harrison and I. M. Stanley (7
November, p. 638) in their suggestion that this drug should be withdrawn by the manufacturers. It is a particularly useful tricyclic preparation in that it has so few side effects and is tolerated so well by most patients. In fact, with anxious patients it is one of the very few antidepressants that they will continue to take in full dosage without complaints of sluggishness, blurred vision, and dryness of the mouth. In the treatment of depressed and anxious patients we must weigh up the pros and cons of each treatment. Against the slight risk of jaundice must be weighed the real benefit to many patients from a drug such as iprindole, and therefore I strongly reject the suggestion that it should be withdrawn.-I am, etc.,

L. J. Ciein.

Long Grove Hospital,
Epsom, Surrey.

SIR,-It would be interesting to know how many cases Drs. D. F. Harrison and I. M. Stanley have treated with iprindole for them to have found four cases of apparent allergic hepatotoxicity (7 November, p. 368).

My interest arises from the fact that I have used this tricyclic antidepressant very widely from the earliest days of its production, and while I have not kept formal note of the numbers of patients involved the relevant figure must certainly be little short of a thousand-and in no case have I observed this allergic effect. I am not disputing the causal relationship postulated in the cases quoted, but I would join issue with the suggestion that "as alternative tricyclic drugs are available with little or no evidence of adverse reactions, we would suggest that iprindole be withdrawn by the manufacturers."

For a start, surely the great attraction of iprindole lies in its freedom from side effects, as distinct from allergic phenomena. I know of no other tricyclic antidepressant with comparable freedom from atropine-like propensities. I think we should remember that the charges that Drs. Harrison and Stanley lay against iprindole have been acceptable occasional hazards of chlorpromazine for many years, and this preparation has certainly stood the test of time on its merits despite these. Even if the possibility of occasional allergic hepatotoxicity is accepted without reservation, this implies that the possibility of the rare occurrence of this phenomenon must be weighed against the undoubted value of a most acceptable (in terms of freedom from conventional side effects) drug, which at the worst is indicted with the production of an effect which reverses on withdrawal.

I would mention that I have regularly used iprindole $(15 \mathrm{mg}$. tab.) in dosage up to $180 \mathrm{mg}$. per day, and at the present time one of my patients, a depressive psychotic previously dependent upon maintenance E.C.T. for some time despite the exhibition of other antidepressants, is maintained at a reasonable level of freedom from symptoms with iprindole $105 \mathrm{mg}$. t.d.s. (315 mg. per day), without any side effects whatsoever In the light of this sort of experience hope Drs. Harrison and Stanley will forgive my expression of concern at their suggestion that such a useful drug should no longer be 